\title{
June 1953
}

\section{The Journal of}

\section{Laryngology and Otology \\ EDITED BY}

WALTER HOWARTH

ASSISTANT EDITOR

R SCOTT STEVENSON

WITH THE COLLABORATION OF

G. H. BATEMAN V. E. NEGUS R G. MACBETH

\section{Contents}

Rhythame Palital MYoclonUs - . . D. L. Ghabwick and RONALD MACBETH

MYRREGITIS BULLOSA HFMORRHAGICA-ITS RKLATIONSHIP TO OTOGENIC ENCKMHALTTYS AND Cranial NERVE Paralyses. . .

J. D, K, DAWES

MODERA DEVkLopMents iN PURE TONE AUDIOMETRY AND thEIR Application to thr Clinicat. Dinganosis of Ento-Organ Dearkess

SOME IMPERFECTIONS OF THE FREE-FIELD VOICE Tissts

M. R. DrX and 1. D. Hoon P. F. Kine

Clinteat. Recordos-

ChOANAL Atresia-A MANHFESTATION OR THE TRTACHER COLLINS' SYNDROMK

K. Avc. MeTseHi $i$ and TEITA WYNTER-WEDDERBURN

ABRRKANT CANINE TOOTH IN THE NOSF A. B. N RAo

Chinteat. Note on the Use of a long Acting L.OCXL ANASTHETIC AGENT IN tHE CONTKOL

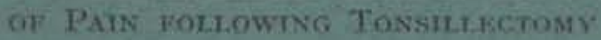

J. C. Camerie.t.

Generat. Notes

\section{London}

\section{Headley Brothers Ltd}

rog Kingsway $\mathrm{WC}_{2}$

Annual Subscription $£_{3} / 3 / 0$ net, U.S.A. \$10 Montbly, $7 / 6$ net post free 


\title{
The Journal of \\ Laryngology and Otology
}

(Founded in 1887 by Morkt. MACkenzie and Norris WolFEnDEN)

\author{
EDITED BY \\ WALTER HOWARTH
}

ASSISTANT EDTTOR

R. SCOTT STEVENSON

$\begin{array}{lll}\text { G. H. BATEMAN } & \text { V. E, NEGUS } & \text { R. G. MACBETH }\end{array}$

1. Original Articles are accepted on the condition that they have not been published elsewhere.

2. Manuscripts should be typewritten, on one side only of the paper, and well spaced.

The Harvard system of recording references should be used, e.g. Green, C., and Brown, D. (1951) J. Laryng., 65, 33 .

It is most important that authors should verify personally the accuracy of every reference before submitting a paper for publication.

3. Galley proofs and engraver's proofs of illustrations are sent to the author. Corrections, which should be kept to a minimum, must be clearly marked, and no extra matter added.

4. Authors will be expected to pay for the cost of illusti-cion blocks. An estimate of the cast will be provided.

5. Orders for reprints should be sent when returning galley proofs, and for this purpose special forms are supplied.

6. Authors of original communications on Oto-Laryngology in other journals are invited to send a copy, or two reprints, to the Journal of Laryngology. If they are willing, at the same time, to submit their own abstract (in English, French, Italian, or German) it will be welcomed.

7. Editorial communications may be addressed to THE EDrros Joumal of Laryngology, c/o HEADLey Brotriers LTD, 109 Kingsway London W C2.

8. The annual subscription is three guineas sterling (U.S.A. \$ro,) post free, and is payable in advance.

9. Single copies will be on sale at 75 . 6d. each; copies of parts up to Vol. LXIII may be purchased at 45 , each.

to. All subscriptions, advertising and business communications should be sent to the publishers, Headiey Brothers LTD, 109 Kingsway London $\mathrm{WC}_{2}$.

\section{United States of America}

Orders for this Journal may be sent cither through a local bookseller, or to Messrs G. E. Strecuert \& Co., 31-33 East roth Street, New York, or they may be sent direct to the publishers, HEADLEY BroTHERS LTD, log. Kingsway London W C 2, England.

Please mention The Journal of Larygology when replying to advertisements 


\section{T H E \\ HALLPIKE - BLACKMORE MONOCULAR EAR MICROSCOPE*}

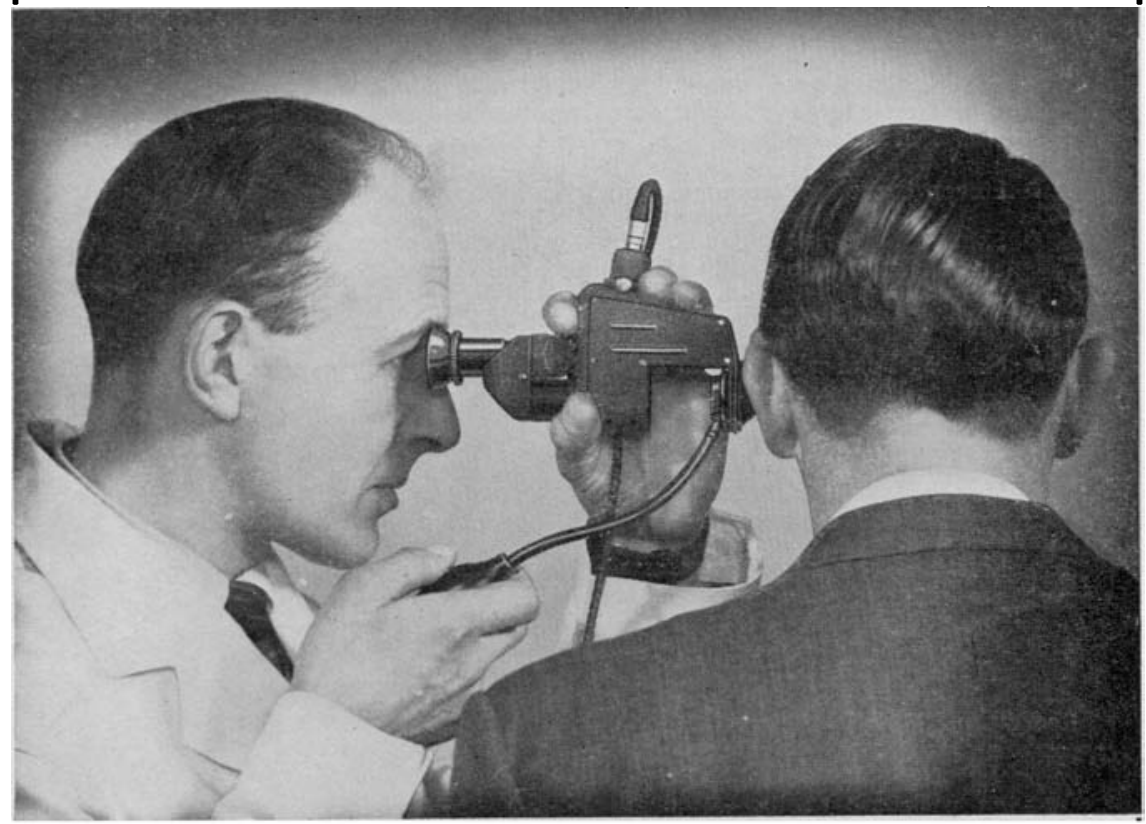

Patt. appl. for

THIS new instrument represents an important contribution to otology. It facilitates accurate clinical diagnosis and operative work of high precision.

- Intense light from 12 watt, silvered, pre-centred lamp.

- Unique dazzle-free optical system provides a critically defined image of the entire tympanic membrane at optimum $\times 6$ magnification.

- Variable field of view controlled by iris diaphragm in eyepiece to ensure total exclusion of reflexions from speculum walls.

- Ample space for insertion of operating instruments.

- Complete in carrying case with built-in transformer to permit use of the instrument on ward rounds, in consulting-rooms or theatre.

* J. Laryng. (1953), 67, 108.

39 WIGMORE STREET LONDON W.1

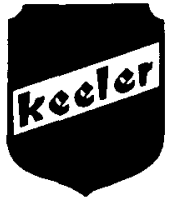

617 S. 52nd STREET PHILADELPHIA 43

Please mention The Journal of Laryngology when replying to advertisements 


\section{AMPLIVOX MODEL 61 \\ THE CLINICAL AUDIOMETER OF INTERNATIONAL REPUTE}

"Messrs. Amplivox were among the first firms to produce an audiometer in this country, and their larger model is one of the best instruments of the kind now made in the world at a competitive price." - The LANCET, 23-12-50.

- Eleven exact test frequencies 125-12,000 c.p.s.

- Simplified hearing loss dial. The same set of figures is read for both bone and air conduction at all frequencies, and for speech.

- Bone conduction tests can be made from 125-4,000 c.p.s.

- Masking Tone calibrated in decibels, permitting accurate control of masking.

- Double Air receivers enable test tones to be switched instantly from ear to ear.

- Speech test circuit monitors speech level, permitting accurate measurement of hearing loss for speech.

- Loudness Balance Control establishes presence of recruitment in monaural deafness.

- Automatic voltage compensator.

Recruitment Test Set accessory establishes presence of recruitment by amplitude modulation, enabling each ear to be tested independently.

Speech Turntable and Englishmade Harvard Spondee records also available.

Full details are available from the manufacturers who will gladly arrange demonstrations if required.

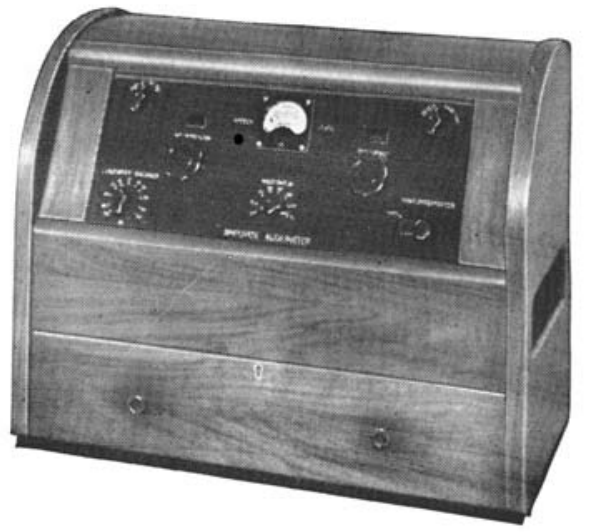

\section{The Basic Instrument of Modern Otology}

ACCURATE • COMPLETE • SIMPLE TO OPERATE AMPLIVOX LTD., 2 BENTINCK ST., LONDON, W.I (Welbeck 259I)

Please mention The Journal of Laryngology when replying to advertisements 


\section{THE ARDENTE}

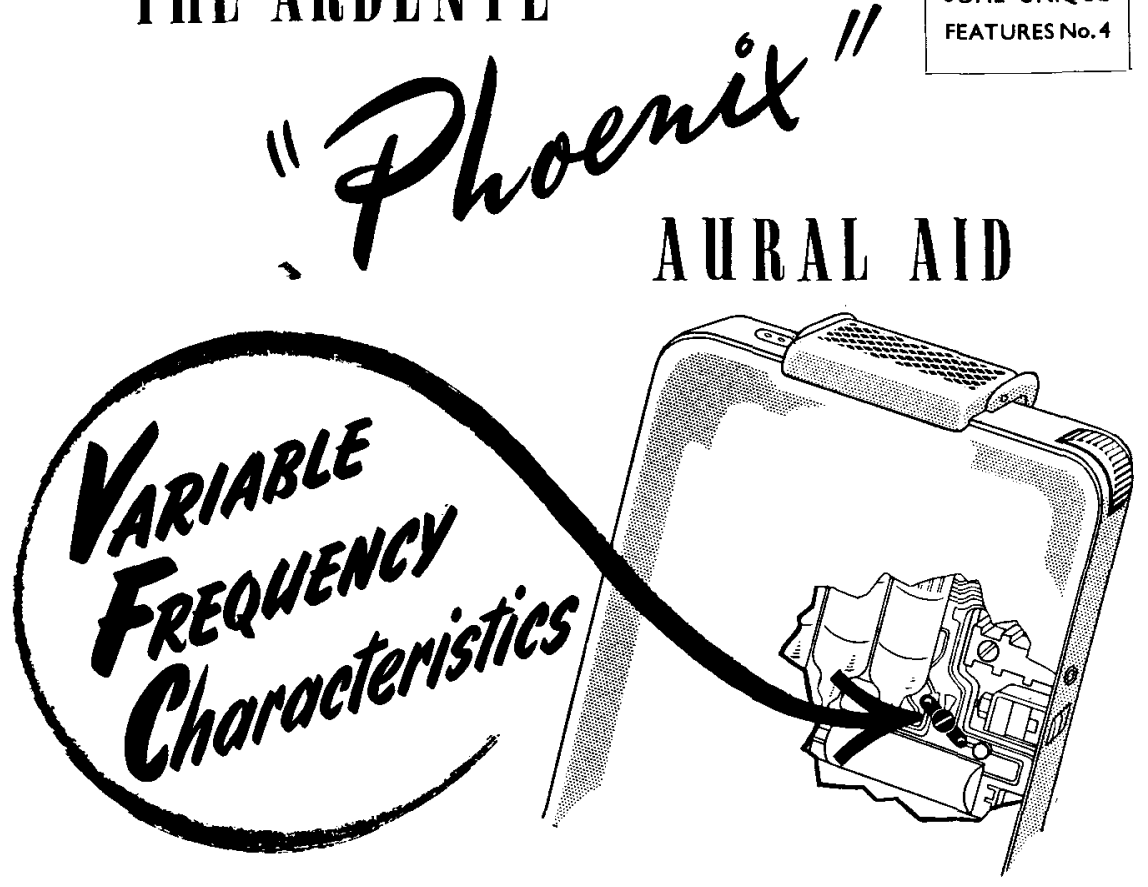

Variations of the frequency-gain characteristics are obtained in the 'Phoenix' by altering the low-frequency characteristics while leaving the high frequencies untouched. A three-position preset switch is incorporated. In position 1 the acoustic amplification at the low frequency of 200 cps. is $47 \mathrm{db}$. (224 times); in the second position, $35 \mathrm{db}$. (56 times); and in the third position, $27 \mathrm{db}$. (22.5 times). Thus, for conductive deafness, switch position 1 is used, as this gives maximum low and medium frequency uplift. Position 2 is meant for mixed deafness or for Otosclerotic patients and position 3 for perceptive deaf patients, who require relative preponderance of high-frequency amplification. A further variation is obtained by using two types of electro-magnetic insert earpieces. One of these accentuates the medium frequencies and the other the higher frequencies.

The 'Phoenix' embodies many new features in aural aid technique, including:

Exceptional suppression of "clothes-rubbing' and all unwanted background sounds.

Automatic Volume Limitation (A.V.C.) for protection against sudden loud sounds.
Unique printed wiring for stable characteristics over long periods of use.

Immediate servicing, by the simple interchange of plugged parts.

For further particulars of the Ardente 'Phoenix' and of our well-known '7-Days Home Trial" scheme, please apply to:

\section{THE ARDENTE HEARING REHABILITATION UNIT}

Ardente House, 309 Oxford Street, London, W.1.

Telephone MAYfair 7917

Please mention The Journal of Laryngology when replying to advertisements 


\section{THE SYRINGING}

\section{OF EARS}

\section{UNDER PRESSURE}

\section{CAN NOW BE AVOIDED}

\section{CERUMOL}

ear drops break up and dissolve

impacted wax in the external auditory meatus

saving time and trouble

in the Surgery and First-Aid Room

Cerumol was clinically tested in a London hospital and is accepted for use in a large number of hospitals and general practices throughout the country.

Price under the National Health Scheme, 2s. 3d. per 10 c.c. dropper vial.

Also packed in $2 \mathrm{oz}$. and $10 \mathrm{oz}$. bottles for hospital use.

\section{SAFE - EFFICIENT - ANTI-BACTERIAL SAVES TIME AND TROUBLE}

Obtainable through your Chemist

\section{CERUMOL}

Professional Sample and a descriptive folder with directions for use available on request to the Distributors:-

TAMPAX LTD., Medical Dept., 110 Jermyn St, London, S.W.1. Phone: WhI 8696

Please mention The Journal of Laryngology when replying to advertisements 


\section{THE INSTITUTE OF LARYNGOLOGY \& OTOLOGY} 330/332 GRAY'S INN ROAD, LONDON, W.C.1

(University of London)

Intensive Course of lectures and demonstrations covering the whole field of the Speciality from July 6 th to 31 st, 1953 . Whole-time course intended to form a theoretical basis in preparation for practical clinical training.

Fee $£ 12$ 12s. Od.

Advanced Revision Course for M.S. and Final F.R.C.S. students, August 10th to October 23rd, 1953. Arranged as part-time course (mostly evenings) to meet circumstances of students holding appointments.

Fee $£ 21$ os. 0 d.

Comprehensive Course especially suitable for D.L.O. Parts I and II students commences on August 31 st, 1953. Whole-time course- 3 months basic sciences in preparation for Part I; 5 months clinical for Part II.

Fee $£ 5210$ s. 0d.

Intensive Course in Endoscopy for senior students and practising members of the Speciality. Whole-time from October 5th to 10th, 1953. Includes practical work.

Fee $f 1010$ s. Od.

Detailed syllabus obtainable from the Dean

\section{BINDING}

\section{Journal of Laryngology \& Otology}

Subscribers wishing to have their Journals bound can do so by sending them to the Publishers.

Volumes are strongly bound in whole dark blue buckram cases, with gold lettering on spine. The cost of binding is 25s. per volume, including postage.

Some missing parts can be supplied at $7 \mathrm{~s}$. $6 \mathrm{~d}$. each, or the whole volume, complete in the above binding, for $88 \mathrm{~s}$.

Publishers' cases can be supplied for Ios., including postage.

HEADLEY BROTHERS LTD, IO9 KINGSWAY LONDON W $\mathbf{C}_{2}$

Please mention The Journal of Laryngology when replying to advertisements 


\section{CONTENTS}

Rhythmic Palatal Myoclonus.

D. L. Chadwick and Ronald Macbeth (Oxford).

Myringitis Bullosa Hæmorrhagica-Its Relationship to Otogenic Encephalitis and Cranial Nerve Paralyses.

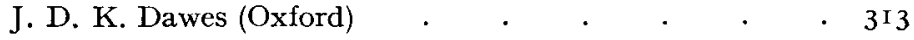

Modern Developments in Pure Tone Audiometry and their Application to the Clinical Diagnosis of End-Organ Deafness. M. R. Dix and J. D. Hood (London)

Some Imperfections of the Free-Field Voice Tests. Wing Commander P. F. King, R.A.F. (London) . . . . $35^{8}$

Clinical Records-

Choanal Atresia-a Manifestation of the Treacher Collins' Syndrome. K. Aug. Mcneill and Leila Wynter-Wedderburn (Kingston, Jamaica) . $\quad . \quad$. $\quad . \quad$. $\quad . \quad$. 365

Aberrant Canine Tooth in the Nose. A. B. N. Rao (Birmingham) 370

Clinical Note on the Use of a Long Acting Local Anæsthetic Agent in the Control of Pain following Tonsillectomy. J.C. Campbell (Carlisle) . . . . . . . . . 372

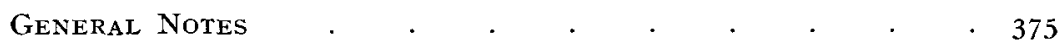

For Advertisement space in this Journal apply to: HEADLEY BROTHERS Ltd, 109 Kingsway London W C 2

Please mention The Journal of Laryngology when replying to advertisements 